\section{ARE ANY OF THE NEBULAE STAR-SYSTEMS?}

THis may seem a bold question, for it is commonly believed that SirWilliam and Sir John Herschel-the Ajax and the Achilles of the astronomical host-have long since proved that many of the nebulæ are starsystems. If we inquire, however, into what the Herschels have done and said, we shall find that not only have they not proved this point, but that the younger Herschel, at any rate, has expressed an opinion rather unfavourable than otherwise to the theory that the nebula are galaxies in any sense resembling our own sidereal system.

Sir William Herschel, by his noble plan of star-gauging, proved that the stars aggregate along a certain zone, which in one direction is double. He argued, therefore, that presuming a general equality to exist among the stars and among the distances separating them from each other, the figure of the sidereal system resembles that of a cloven disc. And as the only system from which he could form a probable ju d g m e n $\mathrm{t}$ - - I mean the planetary systempresented to him a number of bodies, widely separated from each other and each a globe of considerable importance, he reasoned from ana$\log y$ that similar relations exist in the sidereal spaces. This being so, his cloven disc theory of the sidereal system seemed satisfactorily established.

Then, of course, those nebulæ which exhibit a multitude of minute points of light very close together, and those other nebula which, while not thus resolvable into minute points, yet in other respects resemble those which are, came naturally to be looked upon as distinct from the sidereal system. The analogy of this system, in fact, pointed to them as external star-systems, resembling it in all important respects.

Then there were certain other objects, which seemed to present no analogy either to the sidereal system or to separate stars. These objects Sir Wm. Herschel considered to belong to our sidereal system; for he could not put them outside its range without looking on them as objects sui generis, which would have been to abandon the argument from analogy. In order to explain their appearance, he suggested that they might be gaseous bodies, by whose condensation stars would one day be formed.

The value of Sir Wm. Herschel's work is not in the least affected even if science have to reject every one of these opinions. He himself held them with a light hand; he had once held other opinions; and he was gradually modifying these. Had he seen one sound reason for rejecting any or all of them he would have done so instantly. For it belonged to the strength of his character that he was never fettered by his own opinions, as weak men commonly are.

Sir John Herschel did for the southern heavens what his father had done for the northern. He completely surveyed and gauged them. It is commonly believed that the results of his labours fully confirmed the opinions which his father had looked upon as probable.

Let us see if this is so.

Sir W. Herschel thought the Milky Way indicated that the sidereal system has the figure of a cloven disc; Sir John Herschel judges rather that the sidereal system has the figure of a flattened ring. Sir Wm. Herschel thought the stellar nebulæ are probably external galaxies; Sir John gives reasons for believing that they lie within our system, and Whewell considered that these reasons amount to
absolute proof.

It has been further believed and stated that the researches of the elder Struve go far to confirm the opinions put forward by Sir W. Herschel as probable.

Let us inquire how far this is true.

Struve found that the numbers of stars of given magnitudes ex hibit nearly the same proportion in different directions. Thus supposing that in a given directicn there are three times as many stars of a certain magnitude as there are of the nexthighest magnitude, then in other directions, also, the same relation is observed. This is a very striking law ; but to mahe it serve as a proof of the opinion which Sir William Herschel had put forward as probable, it would be necessary that another law should be exhibited. For clearly, if that opinion were just, it would be easy to calculate what the relation should be between stars of different magnitudes. Had Struve been able to show that the numbers actually seen corresponded to the relations thus calculated, he would have gone far to render that view certain which Herschel always spoke of as merely an assumption.

But Struve found no such law of stellar distribution. On the contrary, he found a law so different, that in order to force the facts into agreement with Sir William Herschel's views about the sidereal system, he had to invent his famous theory of the extinction of light in traversing space. Now, according to this theory, we cannot see to the limits of our sidereal system, even though we could increase the powers of our telescopes a million-fold; so that if the theory is true, the question which lieads this paper is at once disposed of. Obviously, we cannot see 
galaxies beyond the sidereal system if we cannot see to the limits of that system. And I may note in passing that (independently of Struve's theory) the most powerful telescopes cannot render visible the most distant stars of our sidereal scheme; so that if the nebula are really external galaxies, the stars we see in them must be enormously greater than those in our galaxies, supposing Herschel was right in thinking these tolerably uniform in magnitude.

Before proceeding to exhibit the evidence which has led me to the conviction that the nebula belong to our sidereal system, I may mention some reasons for believing that if Sir William Herschel's labours in the sidereal heavens were to be begun now, not only would he not have been led to adopt as probable the view on which he formed his opinions, but he would have rejected it as opposed to known analogies.

He had argued that because the planetary system exhibits a definite number of bodies separated by wide distances, therefore analogy should lead us to regard the sidereal system as similarly constituted, though on a much larger scale. This was perfectly just. Despite the various differences which no one recognised more clearly than he did, this view was the only one he could safely adopt for his guidance, ninety years ago.

But would not he have been the first to reject that view if he had known what we now know of the solar system? If he had known that besides the primary planets, there are hundreds of minute bodies forming a zone between the orbits of Mars and Jupiter; that the rings of Saturn are formed of a multitude of minute satellites; that innumerable meteor-systems circle in orbits of every conceivable degree of eccentricity; that near the sun these systems grow denser and denser; that the comets of the solar system must be counted by millions on millions; that, in fine, every conceivable form of matter, every conceivable degree of aggregation, and every conceivable variety of size, exists within the limits of the solar system, -would he, then, have been led by analogy to recognise in the sidereal system only discrete stars and masses forming into stars?

From a careful study of all that Sir William Herschel has written, I feel certain, that in the case I have imagined, he would have been prepared, even before commencing his labours, to expect precisely that variety of matter, size, and aggregation, which modern observations, rightiy understood, prove actually to exist within the range of the sidereal system.

The Herschels, father and son, discovered about 4,500 nebula. Other observers have brought up the number to about 5,400. When these are divided into classes, it appears that some 4,500 must be looked on as irresolvable into discrete points of light. But of these the greater proportion so far resemble resolvable nebulæ as to lead to the belief that increase of optical power alone is wanting to resolve them.

Taking these irresolvable nebulæ, however, as we find them, and marking down their places over the celestial sphere, we recognise certain peculiarities in their arrangement. In the northern heavens they gather into a clustering group as far as possible from the Milky Way. In the southern heavens they form into streams, which run out from a region nearly opposite the northern cluster of nebula; but the extremities of the streams are the region where nebulæ are most closely crowded. The Milky Way is almost clear of nebulæ.

This withdrawal of the nebulæ from the Milky Way has been accepted by many as clearly indicating that there is no association between them and the sidereal system. The opinion of the Herschels, if they had been led to pronounce definitively on this point, would have been different, however; for the younger Herschel quotes (as agreeing with it) a remark of his father's to the effect that the peculiar position of the northern nebular group is not accidental. If not accidental, it can only be due to some association between the nebular group and the galaxy. Every other conceivable explanation will be found to make the relation merely apparent-that is, accidental, which neither of the Herschels admit.

But yet stronger evidence of association exists ; evidence which I do not hesitate to speak of as incontrovertible. Space will only permit me to treat it very briefly.

There is a certain well-marked stream of nebulæ in the southern heavens leading to a well-marked cluster of nebula. There is an equally well-marked stream of stars leading to an equally weli-marked cluster of stars. The nebular stream agrees in position with the star-stream, and the probability is small that this coincidence is accidental. The nebular cluster agrees in position with the star-cluster, and the probability is still smaller that this second coincidence is accidental. Such are the separate chances. It will be seen at once, therefore, how small the chance is that both coincidences are accidental.

The cluster here referred to is the greater of the celebrated Magellanic Clouds. When it is added that the evidence is repeated point for point in the case of the lesser Magellanic Cloud, the indications of association appear overwhelmingly convincing. If the nebulæ really are associated in this manner with fixed stars, the question which heads this paper is disposed of at once.

But there is yet further evidence.

The nebula pass by insensible gradations from clusters less and less easily resolvable, to nebulæe properly so called, but still resolvable, and so to irresolvable nebulæ. Now clusters are found not only to aggregate in a general manner near the Milky Way, but in some cases (on which Sir John Herschel has dwelt with particular force) to exhibit the clearest possible signs of belonging to that zone. If they then belong to the Milky Way, can any good reason be given for believing that the various other classes of nebulæ are not associated with the sidereal scheme? Where should the line be drawn?

Again, some of the nebulæare gaseous, and all the gaseous nebulæ exhibit the same spectrum. Now, two classes of gaseous nebulæ, the planetary and the irregular nebulæ, exhibit a marked preference for the Milky Way, and therefore we must admit the probability that they, at any rate, belong to the sidereal scheme. But then a large proportion of the irresolvable nebulæ are also gaseous, and as they are formed of the same gases, we see good reason for believing that they also must belong to our galaxy. This, however, brings in all the nebulæ, since the recent detection by Lieut. Herschel of the same bright lines in or rather on the continuous spectrum of a starcluster, shows the great probability which exists that with more powerful spectroscopes all the nebulæ may be found to exhibit these bright lines, that is, to contain these particular gases. I pass over the facts, that many nebulæ are found to be closely associated with stars, and that if any doubt could remain as to the association being real and not apparent, it would be removed by a picture of the nebula $\mathrm{M} \mathrm{I}_{7}$, as seen in Mr. Lassell's great reflector at Malta. The reader will be more interested by the following quotation, which I extract (by permission) from a letter of Sir John Herschel's :-

"A remark which the structure of Magellanic Clouds has often suggested to me has been strongly recalled by what you say of the inclusion of every variety of nebulous or clustering forms within the galaxy, viz., that if such be the case-i.e. if these forms belong to, and form part and parcel of the Galactic system-then that system includes within itself miniatures of itself on an almost infinitely reduced scale; and what evidence, then, have we that there exists a universe beyond-unless a sort of argument from analogy, that the Galaxy with all its contents may be but one of these miniatures of a more vast universe, and that there may, in that universe of other systems on a scale as vast as our galaxy, be the analogues of those 
other nebulous and clustering forms which are not miniatures of our galaxy?"

It will be seen that, while Sir John Herschel is quite ready (shonld the evidence require it) to adopt altogether new views about the nebulæ, he is not ready to forego the grandeur of those noble views of the universe which he and his father have established, thereby earning the well-deserved gratitude of every lover of astronomy.

And then with regard to the actual form of our galaxy or Milky Way, the figure introduced shows that its apparent one as projected on the heavens may really be due to an arrangement differing both from the cloven disc or flattened ring, a point to which I shall return in a subsequent article.

\section{RICHARD A. PROCTOR}

\section{THE CROSSNESS WELL-BORING}

THIS boring, which was commenced by the Metropolitan Board of Works for the purpose of supplying the engines and dwelling-houses at Crossness with pure water, has, as may be seen from the accompanying diagram, reached a depth of $96 \mathrm{r}$ feet without piercing the Lower Greensand, where it was expected a good supply would be found.

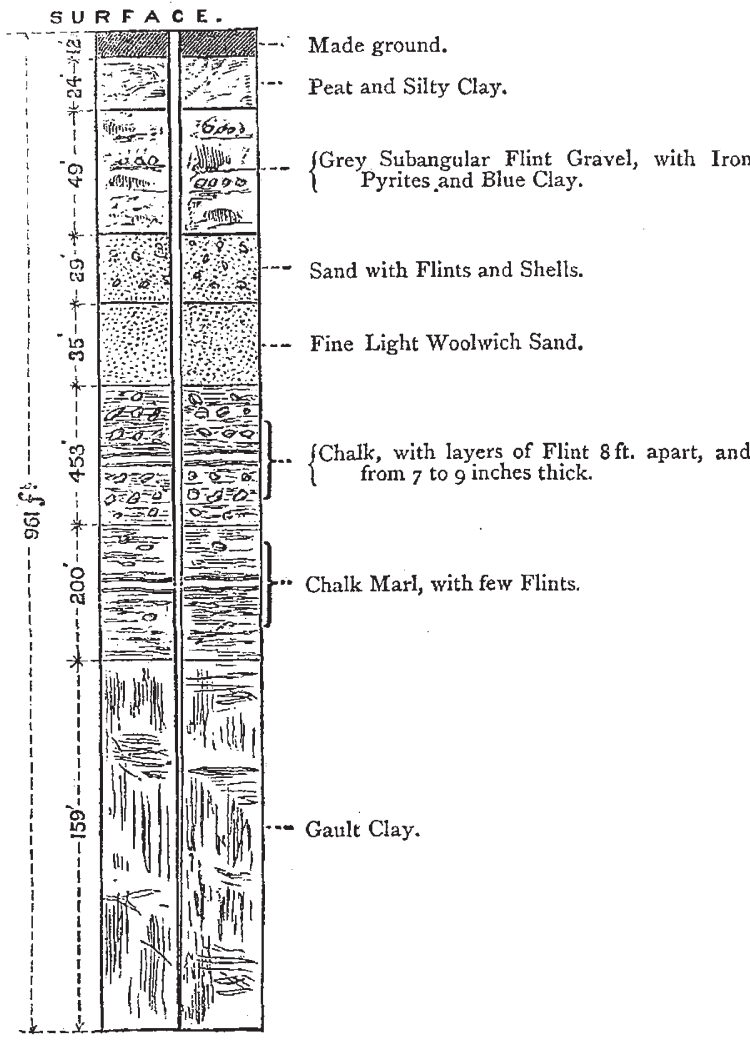

Section of Crossness Well-boring.

In consequence of the great difficulties attending the extraction of broken rods, \&c., from the boring at that great depth, together with the uncertainty of the Lower Greensand being present, the boring has been discontinued. This is much to be regretted, as, if persevered with for a further depth of 40 or 50 feet, it would undoubtedly pass through the gault, which seldom exceeds 200 feet in thickness, 147 feet of which are now entered, and would thus add to the knowledge we at present possess of the substratum of London.

The chalk and gault clay at their outcrop to the north and south of London are underlaid by the Lower Greensand, which is from 150 to 400 feet thick; this, if continuous, as are the chalk and gault, would give a waterbearing strata of great capacity.

But it has been proved that its continuity is broken; as at Harwich, where after boring $\mathrm{I}, 000$ feet through chalk, some carboniferous slates were found, and at Kentish Town, where beneath chalk and gault were found red sandstone and clay, though whether they belong to the Old or New Red Sandstone group, could not be ascertained. Mr. W. Whitaker very reasonably supposes that there is an underground ridge of older rocks crossing the London basin, which was an island when the Greensand was deposited, as the accompanying sketch shows, thus accounting for its absence in the places above mentioned.

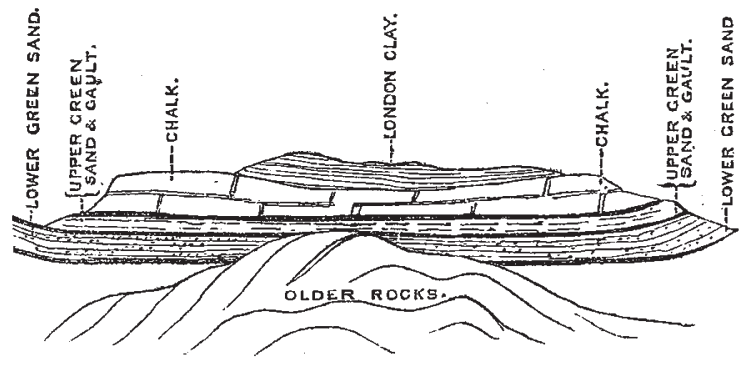

Section across London Basin, showing Probable Position of Ridge of Old Rocks.

If the Crossness boring were continued, and the Greensand were not found, the direction in which this ridge runs would be ascertained, and thus would be prevented much fruitless outlay to those contemplating well-boring; in addition to which, some important facts connected with the London water supply would be made known; further, it might decide the question as to the existence of the coal measures beneath London, at a practicable depth, which, it will be admitted, is a question of universal interest. Under these circumstances, surely Government aid ought to be invoked, as the Board of Works are unwilling to proceed with the boring on their own responsibility.

\section{UTILISATION OF SEWAGE}

THE British Association Committee on the Treatment and Utilisation of Sewage has requested us to state that a number of towns and private. individuals have already sent in or promised subscriptions for defraying the expenses of the contemplated investigation referred to in the circular published in NATURE of the 2nd of December, and that a Special Meeting of the Committee will be held on the 15 th of February next to decide what further steps are to be taken in furtherance of the object in view.

The Committee therefore requests that town and district authorities who have not yet replied to the circular will at their earliest convenience communicate with the Committee, and state what sum will be subscribed; or, if it be decided not to subscribe, what is the reason for declining.

Should the total amount subscribed be insufficient for adequately continuing the inquiry, it is the intention of the Committee to return the subscriptions received.

The following Towns and Districts have subscribed, or signified their disposition to do so:-Stoke-upon-Trent, Exeter, Plymouth, Devonport, Paisley, Coventry, Oxford, Maidstone, Torquay, Wakefield, Dewsbury, Hereford, West Hartlepool, Kendal, Weymouth, Enfield, Penzance, Balsall Heath, Bromley, Bridport, Malvern, Abingdon, Atherton, Toxteth Park, and Walton-on-the-Hill. 